\title{
A SEGURANÇA HUMANA NO CONTEXTO DE UMA CIDADE EDUCADORA
}

\section{REIS FRIEDE}

Mestre e Doutor em Direito, Professor Adjunto da Universidade Federal do Estado do Rio de Janeiro (UNIRIO), Professor do Programa de Pós-Graduação em Desenvolvimento Local da UNISUAM, Professor do Mestrado Profissional em Gestão do Trabalho para Qualidade do Ambiente Construído da USU.

País: Brasil Estado: Rio de Janeiro Cidade: Rio de Janeiro

Email de contato: assessoriareisfriede@hotmail.comＯRCID: http://orcid.org/0000-0001-9316-3690

\section{RESUMO}

Este artigo tem como intuito apresentar um novo modelo de segurança pública, a segurança humana, ampliando o conceito de segurança que tradicionalmente estava focado na ideia de defesa do território. Discorre sobre sua relação com os Objetivos do Desenvolvimento Sustentável e como pode ser aplicado junto ao conceito de cidade educadora, por ser esse um caminho possível para o pacifismo que se almeja, como também do desenvolvimento sustentável e da igualdade de oportunidades para todos. A abordagem metodológica empregada foi a qualitativa, tendo sido feita uma pesquisa bibliográfica que levantou artigos acadêmicos e documentos elaborados pelo governo e pelas instituições que tratam dos temas abordados. O material selecionado foi lido por uma perspectiva crítica analítica.

Palavras-chave: Segurança humana. Cidade educadora. Desenvolvimento sustentável.

\section{ABSTRACT HUMAN SECURITY IN THE CONTEXT OF AN EDUCATING CITY}

This article aims to present a new model of public security, the human security, broadening the concept of security, which was traditionally focused on the idea of defense of the territory. It discusses its relationship with the Sustainable Development Goals and how it can be applied to the concept of the educator city, as this is a possible path to the desired pacifism, as well as sustainable development and equal opportunities for all. The methodological approach used was the qualitative, having been made a bibliographical research that raised academic articles and documents elaborated by the government and the institutions that deal with the addressed subjects. The selected material was read from a critical analytical perspective.

Keywords: Human security. Educator city. Sustainable development.

Data de recebimento: 09/09/2019 - Data de aprovação: 16/06/2020 
O texto a seguir foi produzido, inicialmente, como uma palestra pronunciada na Assembleia Geral do Comitê Permanente da América Latina para Prevenção do Crime (COPLAD), programa do Instituto LatinoAmericano das Nações Unidas para Prevenção do Crime e Tratamento do Delinquente (ILANUD), que se realizou em abril de 2019 na cidade do Rio de Janeiro. O evento teve como objetivo abrir os trabalhos de apresentação do Relatório Geral da América Latina para o $14^{\circ}$ Congresso das Nações Unidas sobre Prevenção do Crime e Justiça Criminal, que a ONU inicialmente realizaria em 2020 na cidade de Tóquio, mas que foi adiado para o ano de 2021 por conta da pandemia de COVID-19.

o COPLAD foi instalado em 2016, por iniciativa do ILANUD, e busca alinhar o tema da prevenção do crime com o documento "Transformando nosso mundo: a Agenda 2030 para o desenvolvimento sustentável" (ONU, 2015), que reúne as metas que os Estados-membros das Nações Unidas concordaram, por unanimidade, atingir até 2030. Na Agenda 2030 constam os novos Objetivos do Desenvolvimento Sustentável (ODS), que resultaram de negociações entre diversos governos, entre eles o Brasil. O acordo a que se chegou abrange 17 Objetivos e 169 metas, que envolvem temas diversificados.

O COPLAD também tem a função de discutir a elaboração do planejamento institucional e pedagógico para a implantação da Universidade Mundial de Segurança e Desenvolvimento Social das Nações Unidas no Brasil. Esse modelo de universidade tem como objetivo colocar em prática um novo modelo de segurança pública, a segurança humana, ampliando o conceito de segurança que tradicionalmente estava focado na ideia de defesa do território.

Partindo da fala realizada no evento, e a ampliando, se busca discutir neste trabalho, de forma objetiva, o que é o conceito de segurança humana, sua relação com os ODS e como ele pode ser aplicado junto ao conceito de cidade educadora.

Para o desenvolvimento deste trabalho foi realizada uma pesquisa qualitativa, por ser uma interpretação subjetiva do material levantado, de caráter bibliográfica, a partir do levantamento de artigos e materiais científicos em geral.

\section{OS ODS E O DESENVOLVIMENTO SUSTENTÁVEL}

Todos os 17 Objetivos do Desenvolvimento Sustentável (ODS), que compõem o documento A transformação do nosso mundo: a Agenda 2030 para o desenvolvimento sustentável, são integrados e indivisíveis, pois para que cada objetivo alcance o sucesso é preciso envolver temas que são pertinentes a outros objetivos. Eles fazem parte de uma convocatória da ONU para que os governos e as pessoas colaborem na eliminação da pobreza e da fome, na promoção da prosperidade, na proteção do planeta e na garantia da paz entre os indivíduos e os povos. Mas o que é paz? Ela tanto pode ser um estado de tranquilidade e de quietude quanto a ausência de guerra ou violência, entendendo que o estado de não guerra ou não violência não necessariamente significa um estado de tranquilidade.

Em certa perspectiva, os ODM [Objetivos de Desenvolvimento do Milênio] podem ser interpretados como uma nova formatação das agendas de desenvolvimento das Nações Unidas, promovidas desde os anos 1960 
para orientar o esforço estratégico de suas agências na busca por maior prosperidade e bem-estar pelo mundo. Como observa Koehler (2016), essas agendas - estabelecidas pela Secretaria Geral com anuência da Assembleia Geral das Nações Unidas - propunham metas quantitativas de crescimento econômico e, gradativamente, ampliaram o escopo para contemplar medidas de bem-estar social para países em desenvolvimento. Já na segunda "Década de Desenvolvimento" das Nações Unidas, iniciada em 1971, além da reiteração quanto à necessidade de crescimento econômico, mencionava-se a importância de objetivos sociais nas áreas de emprego, educação, saúde e nutrição. A menção ao combate à fome e à pobreza como objetivo fundamental da agenda internacional aparece, segundo a autora, a partir da terceira Década de Desenvolvimento, em 1981, não tendo mais saído das agendas desde então. (JANNUZZI; CARLO, 2019, p. 9).

A Agenda 2030 é um documento importante porque, pela primeira vez, são reunidas dimensões para o desenvolvimento sustentável que sempre eram pensadas de forma separada: econômica, social e ambiental. E vai além, ao colocar como fundamental a igualdade de gênero e o empoderamento feminino para que os objetivos propostos sejam alcançados.

“Tão ambígua quanto usual, a expressão 'desenvolvimento sustentável' remete a uma corrente de reflexões que perdura há mais de vinte anos" (GODARD, 1997, p. 107). Desenvolvimento sustentável é o desenvolvimento capaz de atender às necessidades da sociedade sem comprometer o suprimento dessas necessidades às futuras gerações. Mas o que significa cada um dos termos que compõem o conceito: desenvolvimento e sustentável?

O que é desenvolvimento? Podemos dizer que ele se configura como um dos conceitos mais importantes e mais polêmicos dentro do campo das Ciências Sociais. No período posterior ao final da Segunda Guerra Mundial (1938-1945), entendia-se que desenvolvimento significava crescimento econômico e isso levou a uma predominância de economistas discutindo o tema. Mas, ao mesmo tempo, outras áreas também buscaram contribuir no debate e ampliaram o conceito ao valorizar os direitos sociais e humanos que, não apenas, mas principalmente, se traduziram em publicações e compromissos da ONU.

Mobilizador de vontades de mudança e de transformação das sociedades e dos indivíduos, tem servido também para avaliar e classificar o seu nível de progresso e bem-estar. Presente em várias áreas disciplinares, deu corpo a diversas teorias da mudança mas também galvanizou e avaliou práticas e intervenções. É, desse ponto de vista, um dos conceitos com mais possibilidades de alimentar diálogos (ou confusões) interdisciplinares e de estabelecer pontes ou rupturas entre a teoria e a prática. Por isso, nem sempre, na sua abordagem, foi fácil estabelecer fronteiras entre a teoria, a ideologia, a doutrina, a utopia e as práticas sociais. (AMARO, 2003, p. 1).

Sustentável é aquilo que se consegue sustentar, e quando o conceito de desenvolvimento se une ao de sustentável o objetivo é harmonizar economia e ambiente, principalmente dentro do modo de produção capitalista. Ou seja, é conscientizar todas as partes que compõem a sociedade sobre a necessidade de se usar os recursos naturais de modo racional e inteligente, pois somente assim será possível garantir qualidade de vida para todos.

Segundo Feil e Schreiber (2017, p. 268), os termos sustentável, sustentabilidade e desenvolvimento sustentável, mesmo que sejam muito utilizados em diferentes setores, ainda não possuem um consenso como conceito, e os diferentes significados desses termos apresentam uma variação a partir do número de perspectivas e vinculações ao contexto e ao campo de atuação. 
Apesar da ausência de consenso sobre o conceito destes termos, existe a aceitação geral em relação à busca do equilíbrio entre as necessidades do ser humano e o meio ambiente, e em entender suas complexas dinâmicas de interação, para aprofundar e ampliar seu significado (BARBOSA et al., 2014). Outro aspecto de consenso sobre os termos é que representam algo positivo e bom (BAÑON GOMIS et al., 2011). As diversas discussões atreladas aos termos sustentável, sustentabilidade e desenvolvimento sustentável ocorreram visando à obtenção do bem-estar humano em longo prazo por meio da gestão do sistema ambiental humano (ADAMS, 2006; SEAGER, 2008). (FEIL; SCHREIBER, 2017, p. 668).

O conceito de desenvolvimento sustentável está relacionado à sobrevivência da espécie humana, a partir de uma mudança de comportamento e da adoção de uma série de atitudes e inciativas pelo próprio homem. E

nas palavras de Barter e Russell (2012), a definição de desenvolvimento sustentável não se refere a salvar a natureza, mas à internalização de estratégias, agregando, assim, novos recursos para permitir o crescimento econômico e a prosperidade compartilhada por todos. (FEIL; SCHREIBER, 2017, p. 675).

Para Godard (1997, p. 108), o conceito de desenvolvimento sustentável, nos dias atuais, é utilizado para expressar um desejo de "conciliação entre desenvolvimento econômico e a proteção ao meio ambiente do planeta a longo prazo".

Quando a Agenda 2030 reúne dimensões para o desenvolvimento sustentável que sempre eram pensadas de forma separada - econômica, social e ambiental -, e coloca como fundamental promover a igualdade de gênero, ela está propondo "um plano de ação para as pessoas, o planeta e a prosperidade. Também busca fortalecer a paz universal com mais liberdade" (ONU, 2019a). E mais, ela reconhece como o maior desafio do planeta acabar com a pobreza por ser este um dos requisitos fundamentais para o desenvolvimento sustentável.

Nós decidimos acabar com a pobreza e a fome em todos os lugares, até 2030; combater as desigualdades dentro dos países e entre eles; construir sociedades pacíficas, justas e inclusivas; proteger os direitos humanos e promover a igualdade de gênero e o empoderamento de mulheres e meninas; e assegurar a proteção duradoura do planeta e de seus recursos naturais. (ONU, 2019a).

Dentre os 17 ODS que compõem a Agenda 2030, o de número 16 recomenda "Promover sociedades pacíficas e inclusivas para o desenvolvimento sustentável, proporcionar o acesso à justiça para todos e construir instituições eficazes, responsáveis e inclusivas em todos os níveis" (ONU, 2019a). Ao apontar a necessidade de se promover sociedades pacíficas e inclusivas, o Objetivo 16 se torna fundamental para que todos os outros objetivos sejam alcançados. Isso implica pensar que devemos aprender a respeitar e trabalhar com a diversidade e utilizá-la como fator de promoção de uma sociedade em consonância com o desenvolvimento sustentável, na qual existam oportunidades para todos, tornando a vivência mais segura e pacífica.

Nos desdobramentos do Objetivo 16 aparecem como metas "16.1 - Reduzir significativamente todas as formas de violência e as taxas de mortalidade relacionada, em todos os lugares" e "16.b - Promover e fazer cumprir leis e políticas não discriminatórias para o desenvolvimento sustentável" (ONU, 2019b), o que mostra que o desenvolvimento sustentável assume uma dimensão que vai além da dimensão da natureza, e que falar de desenvolvimento sustentável é falar, também, de cidades, do espaço urbano, da vida nesses espaços e de tudo que esteja relacionado a eles, como o combate à violência e a promoção da paz. 
Sociedade pacífica é aquela que almeja a paz, o que nos leva à percepção de que não pode haver desenvolvimento sustentável sem paz e não há paz sem desenvolvimento sustentável (ONU, 2019b). Assim, podemos ampliar a ideia de que a paz, quando está associada a um estado de não guerra, mas sem estar associada ao desenvolvimento sustentável, não significa um estado de tranquilidade. Ou seja, para que o conceito de paz possa ser realizado pela ausência de guerra e presença de um estado de tranquilidade, é necessário que ele esteja associado às diretrizes do desenvolvimento sustentável e, consequentemente, à segurança humana.

\section{SEGURANÇA HUMANA}

Рara que possamos pensar num desenvolvimento que seja capaz de atender às necessidades da sociedade sem comprometer o suprimento dessas necessidades às futuras gerações, ou seja, para que os governos pratiquem o desenvolvimento sustentável, é preciso que as sociedades sejam pacíficas e inclusivas, além de justas. Mas como atender essa necessidade?

A promoção de sociedades pacíficas e inclusivas passa a ser pensada, hoje, a partir de um novo conceito de segurança, a segurança humana. Oliveira (2018, p. 68) define o conceito de segurança humana como "a garantia da sobrevivência individual e do bem-estar com dignidade das pessoas no contexto do convívio social". Como podemos ver, o conceito vai além da ideia mais simples de garantia da segurança física, sendo preciso garantir também a segurança social.

Рara Sorj (2005, p. 40), "o estudo da segurança humana precisa ter um foco mais claro na violência armada, levando em conta também as dimensões institucionais e sociais". Diante desta colocação, um dos caminhos para se entender a importância da segurança humana no corpo social é visualizar os números sobre violência relativos ao local em que se pretende aplicar o conceito.

Segundo dados divulgados no Atlas da Violência 2019 (IPEA; FBSP, 2019), produzido pelo Instituto de Pesquisa Econômica Aplicada/Ipea em colaboração com o Fórum Brasileiro de Segurança Pública (FBSP), no ano de 2017 o Brasil alcançou a marca histórica de 65.602 homicídios. Isso equivale a uma taxa de 31,6 mortes para cada 100 mil habitantes. Historicamente, este é o maior nível de letalidade violenta intencional no país (Figura 1). 


\section{FIGURA 1}

\section{Taxa de homicídio no Brasil}



Fonte: Atlas da Violência 2019 (IPEA; FBSP, 2019).

Quando os números são vistos desmembrados a situação se mostra ainda mais grave: das 65.602 vítimas de homicídio, 59,1\% tinham entre 15 e 29 anos - entre os jovens o risco de morrer assassinado é maior, e se torna um entrave ao desenvolvimento do país; 4.936 mulheres foram assassinadas, ou seja, 4,7 homicídios para cada 100 mil brasileiras; 75,5\% das vítimas de homicídios foram indivíduos negros (definidos aqui como a soma de indivíduos pretos ou pardos, segundo a classificação do IBGE utilizada também pelo SIM - Sistema de Informações de Mortalidade).

Essas taxas tão elevadas de homicídio somente confirmam a existência de um problema que ainda não foi enfrentado pelos governos com políticas que busquem saná-lo em longo prazo. As taxas elevadas somadas ao delineamento do perfil social das vítimas mostram que não só o problema não foi visto com a gravidade que tem como também expõe a baixa visibilidade que determinados grupos apresentam na sociedade, como os negros, pois segundo o Atlas da Violência 2019 (IPEA; FBSP, 2019), para cada indivíduo não negro que sofreu homicídio em 2017, 2,7 negros foram mortos. Mas de qual violência estamos falando?

\footnotetext{
A palavra [violência] origina-se do latim violentia que remete a vis e significa caráter violento ou bravio, força, vigor, potência, emprego de força física. Significa também quantidade, abundância, essência e força em ação. Para Michaud (1989), a etimologia do termo evidencia a ideia de uma força não qualificada que se torna violência apenas quando passa da medida, quando perturba uma ordem, quando rompe acordos e regras que ordenam relações. (BONAMIGO, 2008, p. 205).
}

De forma geral, a palavra violência assume diferentes significados a partir da situação que pretende qualificar. Segundo Misse, "não existe violência, mas violências, múltiplas, plurais, em diferentes graus de visibilidade, de abstração e de definição de suas alteridades" (MISSE, 1999, p. 38). O conceito de violência 
tratado neste artigo está alinhado à colocação de Misse e se refere à violência urbana e seus impactos em todas as esferas da sociedade.

Diante de uma infinidade de manifestações da violência, se torna compreensível que também se busque definições de segurança que possam dar conta dessas variações, ou melhor, que se busque um conceito de segurança que possa englobar o maior número possível dessas variações de violência.

A Guerra Fria foi um conflito que durou logo ao final da Segunda Guerra Mundial (1947) até a extinção da União Soviética (1991) e consistiu num período de disputa entre Estados Unidos e União Soviética pela hegemonia econômica, política e militar do mundo. O conceito de segurança humana surge justamente ao final desse conflito, como fruto de formulações teóricas nos estudos sobre segurança, conflitos e paz desenvolvidas nas décadas anteriores.

O conceito tradicional de segurança centrado no Estado, na sua soberania e integridade territorial, pressupõe que a segurança é conquistada na medida em que se fortalece a sua capacidade militar. Diante dessa concepção, desde a década de 70, emergiram em vários círculos acadêmicos novas propostas e formulações alternativas que questionavam esse conceito tradicional de segurança, tais como: a segurança comum, abrangente, cooperativa, coletiva, global, etc. E todas essas concepções alternativas abriram caminho para que, na década de 90, se formulasse o conceito de Segurança Humana. (OLIVEIRA, 2009, p. 68).

Os Relatórios de Desenvolvimento Humano (RDHs) do Programa das Nações Unidas para o Desenvolvimento (PNUD) têm como objetivo, desde 1990, colocar na pauta de discussão pública questões e políticas que estejam relacionadas ao desenvolvimento humano. Eles também incluem o Índice de Desenvolvimento Humano (IDH) e apresentam dados e análises relevantes para a agenda global.

O Relatório de Desenvolvimento Humano (RDH) éreconhecido pelas Nações Unidas como um exercício intelectual independente e uma importante ferramenta para aumentar a conscientização sobre o desenvolvimento humano em todo o mundo. A publicação tem autonomia editorial garantida por uma resolução da Assembleia Geral das Nações Unidas. A premissa do primeiro RDH, em 1990, era de que as pessoas são a verdadeira riqueza das nações, conceito que guiou todos os relatórios subsequentes. (PNUD, [s.d.]).

O RDH de 1994 é o documento em que aparece, pela primeira vez, o conceito de segurança humana na fala do PNUD:

O conceito de segurança há tempos é interpretado de forma restritiva: como segurança do território à ameaça externa, como proteção dos interesses nacionais na política externa ou como segurança global da ameaça de um holocausto nuclear. Tem sido mais relacionado aos estados-nação do que às pessoas. As superpotências estavam imobilizadas numa luta ideológica - lutando uma guerra fria em todo o mundo. As nações em desenvolvimento, tendo vencido sua independência apenas recentemente, estavam sensíveis a quaisquer ameaças reais ou percebidas às suas frágeis identidades nacionais. Eram esquecidas as preocupações legítimas das pessoas comuns que buscavam segurança em suas vidas diárias. Para muitas delas, a segurança simbolizava a proteção contra a ameaça de doenças, fome, desemprego, crime, conflito social, repressão política e riscos ambientais. Com as sombras escuras da guerra fria recuando, foi possível perceber agora que muitos conflitos estão dentro das nações em vez de entre elas'. (UNDP, 1994, p. 22, tradução nossa).

1 The concept of security has for too long been interpreted narrowly: as security of territory from external aggression, or as protection of national interests in foreign policy or as global security from the threat of a nuclear holocaust. It has been related more to nation-states than to people. The superpowers were locked in an ideological struggle-fighting a cold war all over the world. The developing nations, having won their independence only recently, were sensitive to any real or perceived threats to their fragile national identities. Forgotten were the legitimate concerns of ordinary people who sought security in their daily lives. For many of them, security symbolized protection from the threat of disease, hunger, unemployment, crime, social conflict, political repression and environmental hazards. With the dark shadows of the cold war receding, one can now see that many conflicts are within nations rather than between nations. 
E o Relatório continua apontando que uma consideração básica do conceito deve se concentrar em suas quatros características essenciais: é uma preocupação universal; os seus componentes são interdependentes; é mais fácil de garantir pela prevenção precoce do que pela intervenção posterior; é centrado na pessoa (UNDP, 1994, p. 22-23, tradução nossa).

\begin{abstract}
O conceito de segurança humana é inovador em sua ênfase no cumprimento das leis de defesa dos direitos humanos individuais. Considera-se esta a principal tarefa da ordem internacional, mesmo contra a vontade dos Estados, mencionados como uma das principais fontes de insegurança individual. Todavia, como veremos, apesar de estar centrada nos indivíduos, a segurança humana não pode ser dissociada dos quadros institucionais, em especial dos Estados sob os quais os direitos humanos são (ou não) implementados. (SORJ, 2005, p. 42).
\end{abstract}

O conceito de segurança humana está sintetizado nos 17 ODS que compõem a Agenda 2030. Segundo Eduardo César Leite, secretário Executivo do Coplad: "A Segurança Humana é centrada no bem-estar do povo, assegurando sua sobrevivência para que, assim, possam criar sistemas políticos (sociais, ambientais, econômicos e culturais) que the permitam viver com dignidade, tendo seus direitos respeitados" (INCORPORATIVA PAUTAS, 2018).

O conceito de segurança se diferencia do conceito de segurança humana porque este é mais amplo, porque sua perspectiva se desloca de uma visão centrada no Estado para uma visão centrada no sujeito, no cidadão. Se no período da Guerra Fria o conceito de segurança que prevalecia se voltava para a proteção do território e a garantia da soberania do Estado contra possíveis ataques inimigos, no período posterior a questão principal passou a ser como proteger o indivíduo, e não apenas o território, das ameaças cotidianas.

A segurança agora vai além da visão territorialista, da visão militarizada, e passa a incluir também uma visão humanizada, ou seja, uma visão sobre o humano que habita dentro do território, uma visão que entende que a não proteção do indivíduo frente aos problemas cotidianos também se configura como uma forma de violência.

Para podermos pensar um território que promova qualidade de vida e bem-estar para a população, que gere igualdade de oportunidades e que respeite a diversidade, é preciso se pensar num projeto de cidade que se pretenda pacífica, inclusiva, sustentável e segura. Ou seja, é preciso se pensar numa cidade que seja educadora, por ser esse um caminho possível para o pacifismo que se almeja, como também do desenvolvimento sustentável e da igualdade de oportunidades para todos.

\title{
CIDADES EDUCADORAS
}

Medidas que garantam aos cidadãos seu desenvolvimento integral com relação à educação, à equidade e aos direitos humanos são responsáveis pela diminuição dos índices de violência. O Professor Euler, presidente da Comissão de Educação, Cultura e Turismo do Legislativo de Curitiba (PR), defendeu a indicação da cidade de Curitiba para integrar a Associação Internacional de Cidades Educadoras (AICE), usando Medelín, na Colômbia, como exemplo de cidade que controlou a violência após adotar os princípios da Carta de Barcelona. Segundo Euler, "A carta [de Barcelona] é uma articulação entre desenvolvimento sustentável, direitos humanos e sentimento de pertencimento dos cidadãos em relação à sua cidade" (NOTÍCIAS DO LEGISLATIVO, 2018). 
A Rede Brasileira de Cidades Educadoras (Rebrace)², coordenada pela cidade de Vitória (ES), é composta por 21 cidades: Araraquara (SP), Camargo (RS), Carazinho (RS), Curitiba (PR), Gramado (RS), Guarulhos (SP), Horizonte (CE), Marau (RS), Mauá (SP), Nova Petrópolis (RS), Passo Fundo (RS), Santiago (RS), Santo André (SP), Santos (SP), São Bernardo do Campo (SP), São Carlos (SP), São Gabriel (RS), São Paulo (SP), Soledade (RS), Sorocaba (SP), Vitória (ES); destas, apenas três são capitais e o estado com o maior número de cidades participantes é o Rio Grande do Sul.

A Associação Internacional de Cidades Educadoras, uma organização em rede que tem integrantes de diferentes países ao redor do mundo, acredita que toda cidade tem potencial educativo e que este potencial é capaz de fazer com que todos os cidadãos atinjam o desenvolvimento integral.

O movimento de Cidades Educadoras teve início em 1990, em Barcelona, a partir do pacto selado por um grupo de representantes de cidades que se propuseram a trabalhar juntas para promover a melhora da qualidade de vida de seus habitantes por meio de projetos e atividades que utilizassem o próprio território.

As cidades representadas no I Congresso Internacional das Cidades Educadoras, que teve lugar em Barcelona em Novembro de 1990, reuniram, na Carta inicial, os princípios essenciais ao impulso educador da cidade. Elas partiam do princípio de que o desenvolvimento dos seus habitantes não podia ser deixado ao acaso. Esta Carta foi revista no III Congresso Internacional (Bolonha, 1994) e no de Génova (2004), a fim de adaptar as suas abordagens aos novos desafios e necessidades sociais. A presente Carta baseia-se na Declaração Universal dos Direitos do Homem (1948), no Pacto Internacional dos Direitos Econômicos, Sociais e Culturais (1996), na Declaração Mundial da Educação para Todos (1990), na Convenção nascida da Cimeira Mundial para a Infância (1990) e na Declaração Universal sobre Diversidade Cultural (2001). (PREFEITURA DE VITÓRIA, [s.d.], p. 3).

Quando a cidade é um território que educa, quando é o lugar, além da escola, que assume a função de dar continuidade à formação do indivíduo, pois se vê como o espaço propício para a realização do processo de ensino aprendizagem, então ela é educadora. Uma cidade educadora é aquela que busca alcançar o desenvolvimento econômico reduzindo a pobreza, preservando o meio ambiente e garantindo aos habitantes seus direitos fundamentais, alinhada aos novos Objetivos de Desenvolvimento Sustentável (ODS).

A cidade será educadora quando reconheça, exerça e desenvolva, para além das suas funções tradicionais (econômica, social, política e de prestação de serviços), uma função educadora, isto é, quando assume uma intencionalidade e responsabilidade, cujo objetivo seja a formação, promoção e desenvolvimento de todos os seus habitantes, a começar pelas crianças e pelos jovens. (PREFEITURA DE VITÓRIA, [s.d.], p. 3).

Uma cidade gerida de acordo com princípios educadores procura garantir aos seus habitantes, ao longo de suas vidas, e "em condições de liberdade e igualdade, os meios e oportunidades de formação, entretenimento e desenvolvimento pessoal" (PREFEITURA DE VITÓRIA, [s.d.], p. 6).

O conceito de educação associado ao de cidade vai formar um conceito mais amplo, o de cidade educadora, que se constitui numa cidade com a intencionalidade educativa distribuída em todas as suas esferas, desde os espaços da escola até às políticas públicas. A responsabilidade de formar o cidadão vai além dos muros da escola, embora ela possa e deva ser o espaço privilegiado para isso, porque essa formação é contínua, precisa se atualizar com as mudanças que ocorrem na sociedade, no mundo.

2 Site: https://www.edcities.org/listado-de-las-ciudades-asociadas/ 
Todos os temas desenvolvidos dentro do espaço escolar precisam refletir no entorno da escola, do local ao global, se não for deste modo a educação oferecida perde seu sentido, é como o médico que indica ao paciente que não fume mantendo um cigarro entre os dedos. É preciso envolver o bairro, a cidade, no processo de educar. E como uma cidade pode se envolver no processo educativo da população? Quando ela conhece seu território, conhece suas necessidades, quais são seus problemas, ou seja, como é a cidade pela visão da população e qual a cidade que se deseja ter.

Um dos problemas que hoje se encontra diluído por toda a sociedade é a violência, que atinge as pessoas independente de sua situação econômica. Encontrar formas de controle e de combate à violência se transformou num desafio para os governos. Se uma cidade educadora é aquela que respeita os direitos humanos, então o tema da violência é uma das pautas principais em suas ações.

\begin{abstract}
A segurança pública é um processo sistêmico e otimizado que envolve um conjunto de ações públicas e comunitárias, visando assegurar a proteção do indivíduo e da coletividade e a aplicação da justiça na punição, recuperação e tratamento dos que violam a lei, garantindo direitos e cidadania a todos. Um processo sistêmico porque envolve, num mesmo cenário, um conjunto de conhecimentos e ferramentas de competência dos poderes constituídos e ao alcance da comunidade organizada, interagindo e compartilhando visão, compromissos e objetivos comuns; e otimizado porque depende de decisões rápidas e de resultados imediatos. (BENGOCHEA et al., 2004, p. 119-131).
\end{abstract}

Uma cidade educadora é aquela que promove o diálogo entre as forças policiais e a população, como um dos caminhos no combate à violência. Em vez de promover ações repressoras, cria políticas que levem à orientação e suporte aos cidadãos. Vivemos numa sociedade em que as ações tomadas pelo governo para garantir a segurança pública não são vistas de forma positiva pela população de maneira geral, mas, ao mesmo tempo, essa mesma população não tem a percepção de que a segurança pública é responsabilidade de todos, e transfere todas as ações para o governo, que se expressa principalmente nas medidas policiais, se eximindo de qualquer responsabilidade.

\footnotetext{
Vale registrar o que asseverou o colega Delegado de Polícia do Distrito Federal, WILMAR COSTA BRAGA no seu artigo pertinente à Segurança Pública: "Parece ser a Polícia o único órgão responsável pela segurança, mas não é. Apenas tem a função mais árdua de todos os outros, porque atua na garimpagem de criminosos e na execução das Leis, a fim de torná-las efetivas ao exigir o cumprimento das regras sociais e solucionar os seus conflitos. Daí a preocupação que deve ter o dirigente de um órgão policial com o perfil, com a remuneração, com o preparo técnico e operacional, com a coibição dos desvios de conduta, em face da vulnerabilidade com a criminalidade e com o risco de vida". (MARQUES, 2009a).
}

Se o objetivo comum de uma sociedade pacífica é alcançar a paz, por não poder se pensar em desenvolvimento sustentável sem a sua efetividade, então é preciso promover um ideal de segurança que conte com a colaboração e participação de todos, poder público e sociedade, para se atender aos anseios e desejos de todos.

\title{
APLICAÇÃO DA SEGURANÇA HUMANA NUMA CIDADE EDUCADORA
}

Para se pensar em formas que possibilitem a aplicação, em conjunto, dos dois conceitos trabalhados até o momento, segurança humana e cidade educadora, associados aos Objetivos do Desenvolvimento 
Sustentável, é preciso que existam projetos do governo e políticas públicas que promovam e sustentem esse tripé.

O primeiro passo para se pensar numa cidade educadora é que o poder público tenha interesse em aderir à Associação Internacional de Cidades Educadoras. No site ${ }^{3}$ da AICE fica claro que qualquer cidade, para se associar, primeiro precisa se comprometer com os princípios da Carta das Cidades Educadoras, e então seguir os passos abaixo:

Procedimento:

- Aprovação da adesão por parte do órgão de decisão municipal dos políticos eleitos (conselho municipal, conselho plenário, ou outros).

- Cumprir os princípios da Carta das Cidades Educadoras.

- Participar nos canais de debate, intercâmbio e colaboração da AICE.

- Divulgação de suas experiências através do Banco Internacional de Documentos de Cidades Educadoras (BIDCE).

- Pagar a taxa anual correspondente nos prazos previstos.

Os requisitos para formalização do ingresso são os seguintes:

1. Completar todas as seções do pedido de admissão à AICE e adesão à Carta das Cidades Educadoras, assinada pelo prefeito e ratificada pelo órgão decisório municipal de políticos eleitos (conselho municipal, conselho plenário, ou outros).

2. Remeter cópia do acordo do órgão selecionado e a solicitação de ingresso à secretaria da AICE.

3. Pagar a taxa correspondente. (AICE, [s.d.], tradução nossa).

E por que se associar? Serão usados exemplos que mostram como uma cidade educadora pode mudar a vida da população. O Portal Aprendiz publicou em 2015 um artigo intitulado 5 Cidades educadoras que transformaram suas realidades locais pelo aprendizado (PORTAL APRENDIZ, 2015), e dentre as cidades citadas, três são brasileiras: Santos (SP), Sorocaba (SP) e Maranguape (CE).

A cidade de Santos (SP), para concretizar a ideia de que o indivíduo aprende ao longo de toda a vida, investe em políticas públicas que fortaleçam a ligação da comunidade com a escola, além de fazer da escola um ponto de prestação de serviços de saúde e emissão de documentos. Sorocaba (SP) aliou saúde e educação para se repensar e criou em 2005 o Programa Cidade Educadora, Cidade Saudável, e estabeleceu um sistema pedagógico ancorado em três pilares: aprender a cidade, aprender na cidade e aprender com a cidade. Maranguape (CE), distrito de Cachoeira, criou um Ecomuseu comunitário e, com seu passado de cooperação para garantir as colheitas e a posse da terra, aprendeu a trabalhar coletivamente, incorporando todo o público escolar às atividades de educação integral entre a escola e o museu (PORTAL APRENDIZ, 2015).

É possível perceber que iniciativas até mesmo simples podem ser o início de grandes transformações. Mas se essas transformações podem ocorrer a partir de medidas pensadas em cooperação com a sociedade, ao falar do combate à violência vemos que tudo fica mais complexo, porque depende também de mudanças estruturais nas instituições que compõem a sociedade, como a instituição policial, por exemplo, já que a figura da polícia está diretamente associada às questões de segurança.

3 Disponivel em: <http://www.bcn.cat/edcities/aice/estatiques/espanyol/sec_howtojoin.htm/>. 
O que se espera de uma polícia que atua no território de uma cidade educadora é que ela seja uma polícia cidadã, que compreenda a amplitude do conceito de segurança humana e sua efetiva aplicabilidade. Mas o que é uma polícia cidadã?

A Polícia cidadã é a transformação pela qual passou a Polícia de outrora por exigência da Constituição Cidadã e pelo desejo do cidadão. Essa Polícia estabelece um sincronismo entre o seu labor direcionado verdadeiramente a serviço da comunidade, ou seja, uma Polícia em defesa do cidadão e não ao combate do cidadão. (MARQUES, 2009b).

O documento Modernização da Polícia Civil Brasileira. Aspectos Conceituais, Perspectivas e Desafios (BRASIL, 2005), como o próprio nome já diz, foi elaborado com a perspectiva de promover "uma firme autocrítica sobre os fundamentos da prática policial civil brasileira" (p. 4), e foi apresentado ao então Secretário Nacional de Segurança Pública como "resultado dos estudos sobre as atividades da polícia judiciária e de apuração das infrações penais" (idem).

Destacamos abaixo um trecho que demonstra como, já há algum tempo, a relação entre os órgãos responsáveis pela segurança pública no Brasil, aqui pela fala da Polícia Civil, e a população vêm sendo pensada de forma mais pedagógica e colaborativa.

Como definido na Constituição Federal, à Polícia Civil atribui-se a missão de executar a política de apuração das infrações penais e de polícia judiciária, desempenhando a primeira fase da repressão estatal, de caráter preliminar à persecução processual penal, oferecendo suporte às ações de força ordenadas pela autoridade judiciária. Tal empreendimento exige posturas altamente profissionalizadas por técnicas de gestão e ação operativa, tudo conforme a legislação nacional e os tratados internacionais, particularmente, no que se refere ao respeito pelos direitos fundamentais do homem, segundo fartamente gravado no ordenamento jurídico pátrio.

Conquanto esta competência legal não se caracterize pela prevenção de caráter ostensivo, como ocorre com a Polícia Militar, ela também abarca o sentido finalístico de prevenir o delito, seja por dissuasão gerada pela eficiência e eficácia do método repressivo, seja pelo papel proativo de interlocução com a sociedade civil, pelo qual a polícia também desempenha uma função pedagógica, fomentadora das posturas concorrentes do cidadão, na produção da segurança pública.

Neste último sentido, a polícia atua como educadora para a cidadania, comunicando técnicas, recomendando procedimentos e atitudes que resultem em efetiva prevenção ao crime, perfazendo a vocação da chamada polícia comunitária.

Esta vocação também recomenda franca abertura para os influxos da realidade social, especialmente pela correta audição do público usuário, o que é premissa para a superação do papel meramente reativo da atividade investigativa, uma vez que é ali, na dramática realidade do conflito sobre o qual cotidianamente se projeta, o efetivo lugar de produção de um direito penal que rompa com as estigmatizações contra os segmentos sociais hipossuficientes. (BRASIL, 2005, p. 21-22, grifos nossos).

Cremos que o documento supracitado seja um bom exemplo de iniciativa que promova uma melhor relação entre a polícia e a população, e mais, como um agente que pode, pelo papel que exerce no corpo social, educar para a cidadania. 
Uma iniciativa por parte da sociedade civil que se enquadra nos moldes de uma cidade cidadã é a do Instituto Sou da Paz, que criou, em 2003, o Prêmio Polícia Cidadã, para reconhecer, estimular e valorizar o trabalho da boa polícia, cujo objetivo é aproximar os agentes da sociedade e fortalecer o que a polícia tem de melhor; é a própria sociedade civil que faz a avaliação da premiação.

\section{CONSIDERAÇÕES FINAIS}

Analisar os vínculos entre a segurança humana e a cidade educadora ganha relevância à medida que nos permite projetar um território com qualidade de vida e bem-estar, gerando oportunidades iguais e respeito pela diversidade, o que nos leva a um projeto de cidade que se pretenda pacífica, inclusiva, sustentável e segura.

Acreditamos que, ao se comprometer em ser educadora, a cidade amplia seu foco ao observar sua realidade em uma perspectiva integral e humanizada, tendo como compromisso o desenvolvimento sustentável para todos, o que engloba todas as dimensões prescritas nos 17 ODS.

Esse trabalho não se faz em uma única ação, mas se concretiza à medida em que se estabelece como prioridades a segurança e a proteção humana, incluindo nessas prioridades o ambiente no qual o indivíduo se insere.

Torna-se necessário que projetos de governo e políticas públicas sejam estabelecidas para desencadear um conjunto de ações necessárias, mas não podemos nos deter nisso, é imprescindível que seja ampliada a participação dos indivíduos e que estes se tornem cada vez mais conscientes de seu papel de cidadão, responsabilizando-se também pelo projeto de cidade que almejam. Ser cidadão implica em participar ativamente na realização de um projeto de vida social com qualidade e bem-estar.

No mundo de hoje, trabalhar para o alcance de um projeto que privilegie educação e segurança amplas e associadas à responsabilidade com o ambiente, favorece a ampliação dos aspectos humanos e sociais, e estimula ao exercício da cidadania.

\section{REFERÊNCIAS BIBLIOGRÁFICAS}

AICE. Asociación Internacional de Ciudades Educadoras. Cómo asociarse. [s.d.]. Disponível em: <http:// www.bcn.cat/edcities/aice/estatiques/espanyol/sec_iaec.html>. Acesso em: 30 abr. 2020.

AMARO, Rogério Roque. Desenvolvimento - um conceito ultrapassado ou em renovação? Da teoria à prática e da prática à teoria. Cadernos de Estudos Africanos, n. 4, p. 35-70, 2003. Disponível em: <http:// journals.openedition.org/cea/1573>. Acesso em: 29 jul. 2019.

BALLESTEROS, Jesús. Segurança humana, direitos e políticas públicas. Direito \& Justiça, v. 40, n. 1, p. 30-38, jan./ jun. 2014. Disponível em: <file:///C:/Users/mxc/Downloads/16546-64056-1-PB.pdf>. Acesso em: 5 jul. 2019.

BENGOCHEA, Jorge Luiz Paz; GUIMARÃES, Luiz Brenner; GOMES, Martin Luiz; ABREU, Sérgio Roberto de. A Transição de uma polícia de controle para um polícia cidadã. São Paulo em Perspectiva, v. 18, n. 1, p.119-131, 2004. Disponível em: <http://www.observatoriodeseguranca.org/files/a\%20transicao\%20 para\%20uma\%20policia\%20cidada.pdf>. Acesso em: 24 jul. 2019. 
BOBBIO, N. A era dos direitos. Rio de Janeiro: Campus,1992.

BONAMIGO, Irme Salete. Violências e contemporaneidade. Rev. Katál, Florianópolis, v. 11, n. 2, p. 204213, jul./dez. 2008.

BRASIL. Ministério da Justiça. Secretaria Nacional de Segurança Pública. Modernização da Polícia Civil Brasileira. Aspectos Conceituais, Perspectivas e Desafios. 2005. Disponível em: <http://pfdc.pgr.mpf.mp.br/atuacao-econteudos-de-apoio/publicacoes/seguranca-publica/modernizacao_policias_civis.pdf>. Acesso em: 24 jul. 2019.

FEIL, Alexandre André; SCHREIBER, Dusan. Sustentabilidade e desenvolvimento sustentável: desvendando as sobreposições e alcances de seus significados. Cad. EBAPE.BR, Rio de Janeiro, v. 15, n. 3, jul./set. 2017. Disponível em: <https://doi.org/10.1590/1679-395157473>. Acesso em: 24 jul. 2019.

GODARD, Olivier. O desenvolvimento sustentável: paisagem intelectual. In: CASTRO, Edna; PINTON, Florence (Orgs.). Faces do trópico úmido - conceitos e questões sobre desenvolvimento e meio ambiente. Belém: Cejup/UFPA-NAEA, 1997.

INCORPORATIVA PAUTAS. Ribeirão Preto recebe, pela $1^{\text {a }}$ vez, especialista ligado à ONU para falar sobre Segurança Humana. Incorporativa Pautas, 27 ago. 2018. Disponível em: <http://www.pautas. incorporativa.com.br/a-mostra-release.php?id=35946>. Acesso em: 25 jun. 2019.

INSTITUTO SOU DA PAZ. Prêmio Polícia Cidadã. [s.d.]. Disponível em: <http://soudapaz.org/o-quefazemos/desenvolver/sistema-de-justica-criminal-e-seguranca-publica/policia/premio-policia-cidada/>. Acesso em: 07 jun. 2021.

IPEA; FBSP. Atlas da Violência 2019. Brasília: Rio de Janeiro: São Paulo: Instituto de Pesquisa Econômica Aplicada (Ipea); Fórum Brasileiro de Segurança Pública (FBSP), 2019.

ISHALC. Instituto de Segurança Humana para a América Latina e Caribe. Segurança Humana é a Nossa Meta. Disponível em: <http://segurancahumana.com.br/>. Acesso em: 2 abr. 2019.

JANNUZZI, Paulo de Martino; CARLO, Sandra de. Da agenda de desenvolvimento do milênio ao desenvolvimento sustentável: oportunidades e desafios para planejamento e políticas públicas no século XXI. Bahia Análise \& Dados, Salvador, v. 28, n. 2, p. 6-27, jan. 2019. Disponível em: <http://publicacoes.sei. ba.gov.br/index.php/bahiaanaliseedados/article/view/143>. Acesso em: 3 jul. 2019.

MARQUES, Archimedes. A Polícia cidadã e a Sociedade. Conteúdo Jurídico, Brasília-DF, 23 maio 2009a. Disponível em: <https://conteudojuridico.com.br/coluna/284/a-policia-cidada-e-a-sociedade>. Acesso em: 29 maio 2020.

Polícia cidadã depende do empenho da sociedade. Consultor Jurídico, 23 dez. 2009b. Disponível em: <https://www.conjur.com.br/2009-dez-23/policia-efetivamente-cidada-depende-empenho-todasociedade>. Acesso em: 24 jul. 2019.

MISSE, M. Malandros, marginais e vagabundos e a acumulação social da violência no Rio de Janeiro. Rio de Janeiro, 1999. Tese (Doutorado em Sociologia) Instituto Universitário de Pesquisas do Rio de Janeiro (Iuperj), Rio de Janeiro, 1999.

NOTÍCIAS DO LEGISLATIVO. Aprovada integração de Curitiba à Associação de Cidades Educadoras. Curitiba, 3 maio 2018. Disponível em: <https://www.cmc.pr.gov.br/ass_det.php?not=30247\#\&panel1-1>. Acesso em: 2 abr. 2019.

OLIVEIRA, Ariana Bazzano de. O Fim da Guerra Fria e os Estudos de Segurança Internacional: o Conceito de Segurança Humana. AURORA, ano III, n. 5, dez. 2009. Disponível em: <https://www.marilia.unesp.br/ Home/RevistasEletronicas/Aurora/OLIVEIRA.pdf>. Acesso em: 24 jul. 2019. 
OLIVEIRA, Edmundo. O universo da segurança humana. Apoio para publicação: Instituto de Segurança Humana do Brasil. São Paulo - Brasil. Coplad - Ilanud Publication. San José - Costa Rica, 2018.

ONU. Nações Unidas no Brasil. 17 Objetivos para transformar o mundo. Disponível: <https://nacoesunidas. org/pos2015/>. Acesso em: 2 abr. 2019a.

Nações Unidas no Brasil. A Agenda 2030. Disponível em: <https://nacoesunidas.org/pos2015/ agenda2030/>. Acesso em: 3 abr. 2019b.

PEQUENO, Marconi. Violência e Direitos Humanos. Revista de Filosofia Aurora, v. 28, n. 43, p. 135-146, abr. 2016. ISSN 1980-5934. Disponível em: <https://periodicos.pucpr.br/index.php/aurora/article/view/ aurora.28.043.DS07/241>. Acesso em: 3 abr. 2019.

PNUD. Programa das Nações Unidas para o Desenvolvimento. O que é o RDH. [s.d.] Disponível em: <http:// www.br.undp.org/content/brazil/pt/home/idh0/conceitos/o-que-e-o-rdh.html>. Acesso em: 24 jul. 2019.

PORTAL APRENDIZ. 5 cidades educadoras que transformaram suas realidades locais pelo aprendizado. Portal Aprendiz, 7 maio 2015. Disponível em: <https://portal.aprendiz.uol.com.br/2015/05/07/5-cidadeseducadoras-que-transformaram-suas-realidades-locais-pelo-aprendizado/?utm_medium=website\&utm_ source=archdaily.com.br>. Acesso em: 24 jul. 2019.

PREFEITURA DE VITÓRIA. Vitória Cidade Educadora. Carta das Cidades Educadoras. Coordenação da Rede Brasileira de Cidades Educadoras, Vitória-ES. Disponível em: <http://www.edcities.org/redebrasileira/wp-content/uploads/sites/14/2019/03/20171205_carta_cidades_educadoras-VIX.pdf>. Acesso em: 2 abr. 2019.

Programa Cidades Sustentáveis. Disponível em: <https://www.cidadessustentaveis.org.br/institucional/ apresentacao>. Acesso em: 2 abr. 2019.

ROCHA, Raquel Maria de Almeida. O histórico da segurança humana e o (des)encontro das agendas de desenvolvimento e segurança. Revista Carta Internacional, Belo Horizonte, v. 12, n. 3, p. 104-129, 2017.

SORJ, Bernardo. Segurança, Segurança Humana e América Latina. SUR - Revista Internacional de Direitos Humanos, n. 3, ano 2, p. 40-59, 2005. Disponível em: <http://www.scielo.br/scielo.php?script=sci_ arttext\&pid=S1806-64452005000200004>. Acesso em: 24 jul. 2019.

UNDP. United Nations Development Programme. Human Development Report 1994: New Dimensions of Human Security. 1994. Disponível em: <http://www.hdr.undp.org/en/content/human-developmentreport-1994>. Acesso em: 2 abr. 2019.

WHO. World Health Organization. Global consultation on violence and health. Violence: a public health priority. Geneva: WHO, 1996 (document WHO/EHA/SPI.POA.2). 
